\title{
A VIRTUAL RECONSTRUCTION OF A WAVE-POWERED FLOUR MILL FROM 1801
}

\section{Manuel L. Membrilla ${ }^{2}$, Francesc X. Villasevil, ${ }^{1}$ Dolores López ${ }^{2}$, Josep M. Monguet ${ }^{2}$, Joaquim Marquès $^{2}$}

${ }^{1}$ Department of Electronics Engineering, Escola Politècnica Superior d'Enginyeria de Vilanova I la Geltrú, Universitat Politècnica de Catalunya, Spain ${ }^{2}$ Department of Graphic Expression in Engineering, Escola Politècnica Superior d'Enginyeria de Vilanova I la Geltrú, Universitat Politècnica de Catalunya, Spain

ml.membrilla@upc.edu (Manuel L. Membrilla), villasevil@eel.up.edu (Frances X. Villasevil), dolores.lopez@upc.edu (Dolores López),jm.monguet@upc.edu (Josep M. Monguet) jmarques@ege.upc.edu (Joaquim Marquès)

\section{SUBJECT AREA: HISTORY OF ENGINEERING}

\begin{abstract}
Around 1801, Francisco Terrés i Serra designed and developed a sustainable wave-powered flour mill in Vilanova i la Geltrú, a town located on the Mediterranean coast south of Barcelona, Spain. The mill, which was located on the seashore, consisted of a system of paddles driven by waves that provided the energy necessary to pump sea water to a a gathering pond located at a height of five metres above sea level. This water was then fed to a wooden waterwheel that, via a lantern wheel, turned two sets of millstones in the upper room of the mill where the flour was ground.
\end{abstract}

The mill is now located more than 50 metres from the water line due to the sedimentation of the coastline caused by the construction of nearby breakwater walls. Only a small part of the building is still standing, however, and there are no traces of the original hydropower or pumping systems.

Using information gathered by the historian Francisco Conde and original plans of the mill obtained from the Navy Command in Barcelona, we created a virtual reconstruction of the flour mill complex and its hydraulic components and a 3D simulation of how the mill operated.

KEYWORDS: Digital modeling, virtual simulation, sustainable technology, industrial heritage. 


\section{HISTORICAL BACKGROUND}

The coastal town of Vilanova i la Geltrú, located on the Mediterranean coast south of Barcelona, Spain is home to the remains of an original wave-driven flour mill designed and developed by Francisco Terrés i Serra, a carpenter specialised in the construction of water pumping systems for mines and hydraulic machinery for mills and other water-powered applications. Terrés was from a small town, Sant Martí de Riudeperes, in inland Catalonia and we do not know what brought him to Vilanova i la Geltrú in the late 18th century, or what became of him in later years. It is likely, however, that, after witnessing the closure of many river mills and the rising price of flour as the result of drought conditions, our inventor decided to apply his knowledge to create a mill that was not dependent on river flows.

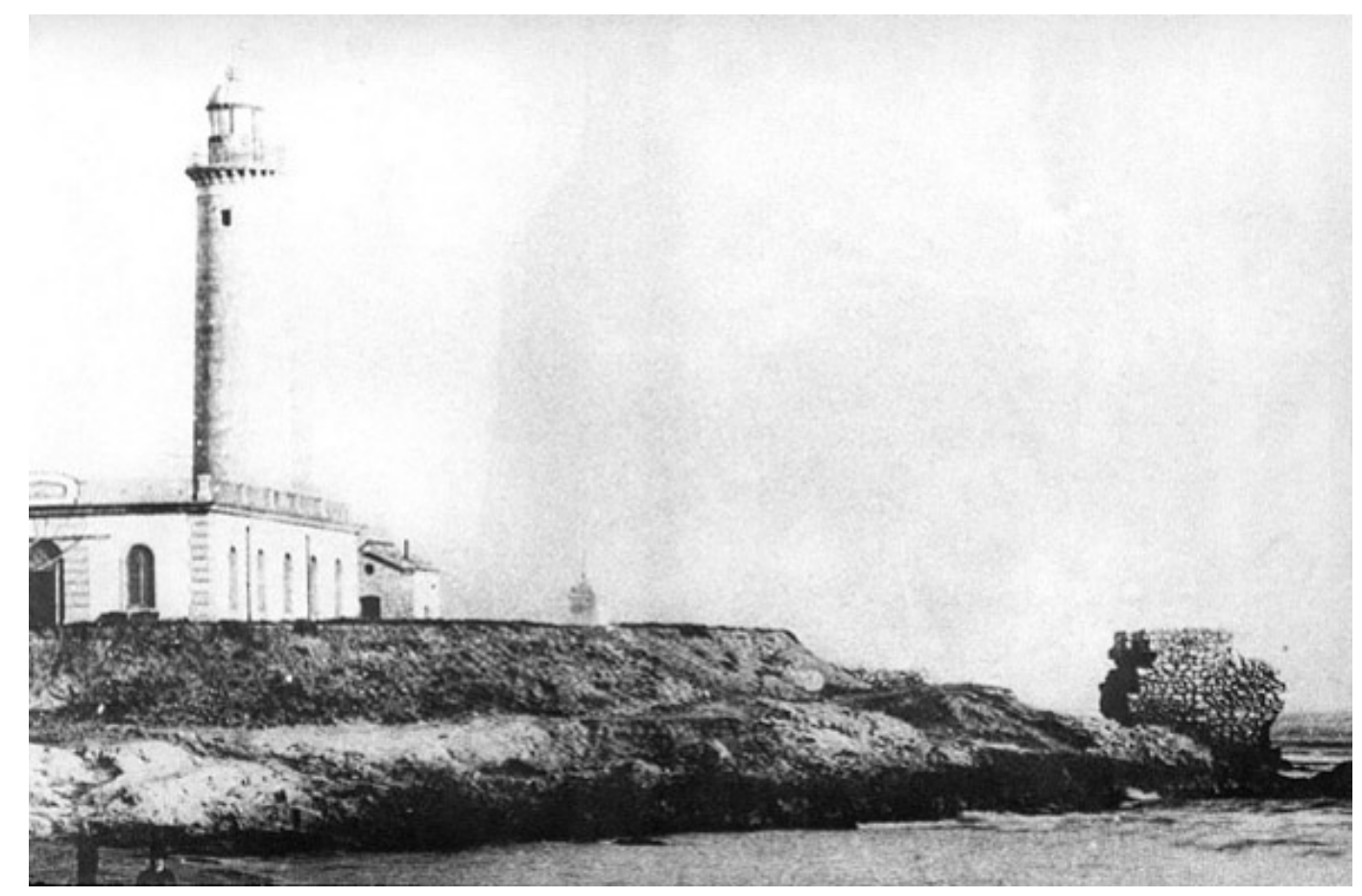

Figure 1. Remains of the mill at the beginning of the 20th century.

The earliest reference to the flour mill dates back to November 1798, in a letter written by the Captain General of the Principality of Catalonia and the Real Acuerdo (a supreme governing authority) to the City Council of Barcelona. Attached to the letter was a copy of a document written by Terrés a few days earlier. The builder claimed to have conceived a system that would use wave energy to move a waterwheel. He highlighted the advantages of a system that would not be affected by changes in river flows and requested funds to pay for its construction. 


\subsection{Steps for construction}

We know that there are numerous historical sources that that we have not been able to locate since the correspondence held by the National Historical Archives in Madrid (which has not yet been analyzed in depth) contains a comment by Terrés that his invention may have been copied by foreigners and a request for the government to look into the matter and lend its support. Neither have we been able to locate the drawings and description of the improvements the inventor made after experimenting with the initial construction.

From the documentation consulted, we can assume that Terrés was willing to take responsibility for the costs associated with building the mill but was of the opinion that such a costly venture would not be worth if it could then be copied by all and sundry. We can therefore presume that he decided to negotiate with the government to secure a patent that would provide for him and his heirs.

\subsection{Possible operational problems}

We know that the mill was operating at some point because a description of the mill published in the newspaper El Diario de Barcelona in August 1801 mentioned that "very white cakes" had been produced thanks to the mill. We can also deduce, however, that the mill had limited effectiveness because there is little or no mention of it in the years that followed and also because Terrés had urgently attempted to raise money to make improvements. The mill was perhaps overly dependent on the sea waves to ensure adequate force and direction of thrust. While excessive force might have broken certain parts, inadequate force would have not generated the power needed by the pistons to pump up the water required to move the waterwheel. It is known that waves rarely impact the coast perpendicular, a fact that would have seriously compromised the performance of the pumps, and consequently, of the mill. Another equally serious problem that the builder undoubtedly had to face was rusting from seawater. To prevent rapid deterioration throughout the mill, the parts would have needed constant protection, which would have been both costly and time-consuming.

Finally, we believe that Terrés cannot fail to have heard about the construction of Spain's first steam engine in Barcelona, news of which was published in 1804. Early prototypes had been already been in use in Europe for several decades but because of their strategic importance, details were zealously guarded by national governments. It is likely that our inventor knew little or nothing about the use of new steam-powered mills throughout Europe. This was also the case with many other inventions, whose fate we know little of.

Just two years after Terrés started struggling to obtain funds to improve his mill, the famous inventor and doctor Francesc Santpons together with industrialist Jacint Ramon set to work with a group of specialist craftsmen to create a reduced-scale prototype of a steam engine. Surely the reports of their work would have spread the news of the enormous power and productivity associated with steam-powered machines abroad. Added to his problems with money, the unpredictable force of the sea, and rusting parts, this news probably dealt a great moral blow to our modest inventor. 
The art of invention has changed over the centuries, with teams of scientists working with skilled operators and the backing of investors having replaced the inventor-craftsman, who took care of practically everything. Another important change is that to-scale prototypes are now built to minimise costs and control possible losses should the invention fail.

\subsection{Current situation}

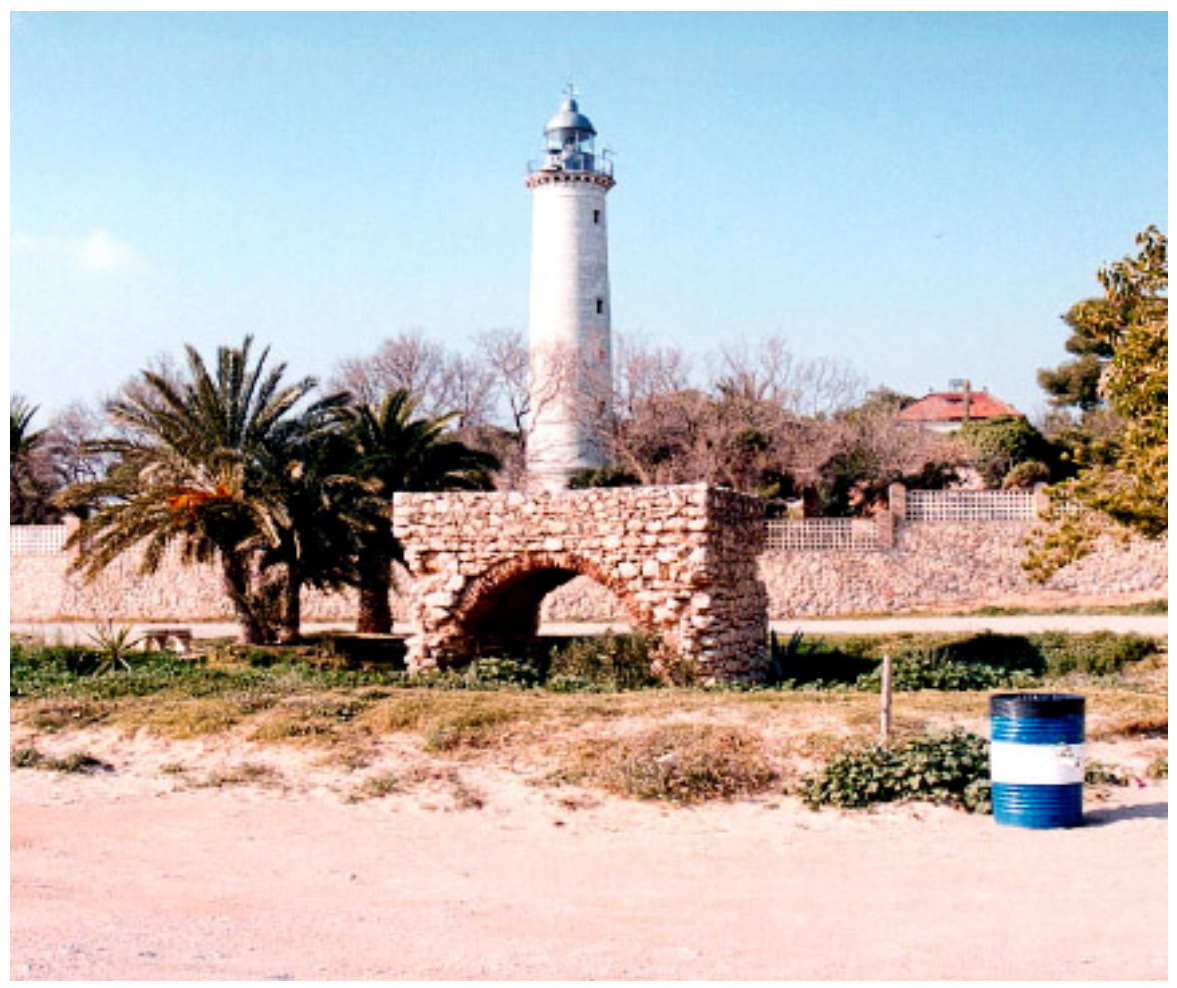

Figure 2. Remains of the mill as it is today.

The mill was in all likelihood abandoned because of its lack of productivity and also probably because Terrés failed to raise the money he needed to make much-needed improvements. We can only presume that the most delicate parts of the complex, i.e., those that needed constant maintenance such as mobile or metal parts, were probably eroded by the sea and that the materials used to build the sections of the mill that housed the millstone and the waterwheel were used in nearby constructions. The surrounding landscape would also have changed with time, first with the construction of Vilanova's first lighthouse, in 1866, later with the completion of the first phase of the port, and later still, with the building of the current lighthouse, which began operating on May 1,1905. Electricity was also brought to the town between 1813 and 1896. Later changes included the building of the first villas in the area and the railway station in 1926. The change that would have had the greatest impact on the mill, however, was undoubtedly the construction of the current port. The breakwater, which was started in the first construction phase and still stands today, led to the build-up 
of large amounts of sand on the shoreline, forming what is now the beach in front of the lighthouse and burying much of the original mill complex.

In 1975, repair work was begun to support the remains of the existing structure. The holes in the walls were repaired and the floor of the gathering pond was covered with a cement slab to prevent the rains from collapsing what had been the most solid part of this complex for the best part of two centuries.

\section{VIRTUAL RECONSTRUCTION OF THE FLOUR MILL}

\subsection{Description of the mill, parts and nomenclature}

Obrador (milling room): The workplace of the miller. This would have contained the millstones and mechanisms necessary for producing flour. The Spanish term obrador is still used nowadays to describe a baker's workplace.

Gathering pond: Pond used to collect the water raised by the pumps to power the waterwheel.

Pump room: Part of the mill housing the pumps. It was located below sea level, with the base of the pumps submerged in water to permit the suction of water. The side walls of this room are visible in some old photographs.

Waterwheel axle support: The description of the flour mill mentions a pillar in the centre of the room under the milling room, which, in conjunction with a similar support on the side wall, bore the weight of the wheel.

Architectural components: The architectural remains that are still visible on the beach in front of the lighthouse correspond to the building that housed the gathering pond. The pond has also been preserved, together with certain features such as two holes through which water was supplied to the wheel below. There are two holes as Terrés initially intended to drive two wheels.

Millstone: Circular stone with a hole in the centre through which the grain to be ground was fed. These stones usually had a spiral groove to help channel out the ground flour. The careful grinding and balancing of millstones was crucial to the process and required an expert hand. The stones were changed quite frequently due to the amount of abrasion they were subject to.

Hopper: Receptacle with an opening in the bottom through which the grain was dropped onto the millstone. These hoppers included a mechanism that allowed the controlled feeding of grain to prevent blockages.

Lantern wheel: Wheel responsible for transmitting the power from the rotating waterwheel to the millstone.

Waterwheel: A wooden wheel with enclosures formed by blades-called buckets-arranged around the wheel to hold water. The weight of the water in the buckets on one side produced the torque needed to turn the wheel, the 
movement of which was aided by the kinetic energy generated by the water striking the blades. The wheel was also fitted with teeth to transmit the movement of the wheel to the lantern wheel.

Tentering (grinding adjustment) system: A wedge system that acted on a wooden plank supporting the axle of the lantern wheel to adjust the gap between the millstones to produce exactly the grade of flour required. The addition or removal of wedges changed the angle of the plank and with this the height of the millstones, which were supported by the axle of the lantern wheel.

Rocker arms: Attached to the tie beams at one end and to an axle at their centre point, these arms transmitted the swinging movement from the tie beams to the connecting rods, thus enabling the pumping of water.

Tie beams: Two parallel beams attached at either end to axles that were attached to rocker arms and pendulums. Their purpose was to transmit the movement of the pendulums to the rocker arms.

Pendulums: The paddles that received the dashing of the waves. Because they were supported by an overhead axle, the movement of the waves produced a swinging movement similar to that of the pendulums. Firmly attached to the top of the pendulums was an arm that stretched perpendicularly backwards. The top of this arm was, in turn, attached to the tie beams.

Connecting rods: These are the metal bars that connected each piston to the rocker arms. They are not exactly connecting rods, however, because they did not convert linear movements into rotary movements. A more correct term, perhaps, would be thrusters.

Pump: A metal cylinder with a piston inside and two valves, one to pump up the water and another to prevent it from returning when the piston was activated.

Elevators: Tubes connected to the pumps to carry the water up to the level of the gathering pond.

Races: Troughs for channelling the water lifted by the pumps to the gathering pond.

All of these mechanisms were designed to harness the force of the waves to power the mill, as follows. The waves hit against the pendulums, causing them to swing. This swinging, or rocking, movement was then transmitted to the pumps through the tie beams and the rocker arms, which replicated the movement of the pendulums. The pumps lifted the water, whose potential energy was used to channel it to the waterwheel, causing it to turn. The movement of the wheel was then transmitted to the millstone via a lantern wheel. Logically, the process is more clearly depicted in the video we have created. 


\subsection{Justification of the virtual model}

In our 3D modeling of the mill, the main objective was to provide as clear a picture as possible of how the mill harnessed the power of the waves to operate the millstone and produce flour. This is primarily a visual work and we strived to provide an as realistic a recreation as possible given the information available and the technical limitations of the equipment used.

On analysing all the documentation collected, it soon became clear that we would be unable to produce an exact replica of the original mill as it was in 1801. To create our model, we had to make many assumptions and decide on many major and minor details, particularly with relation to the appearance of the original building.

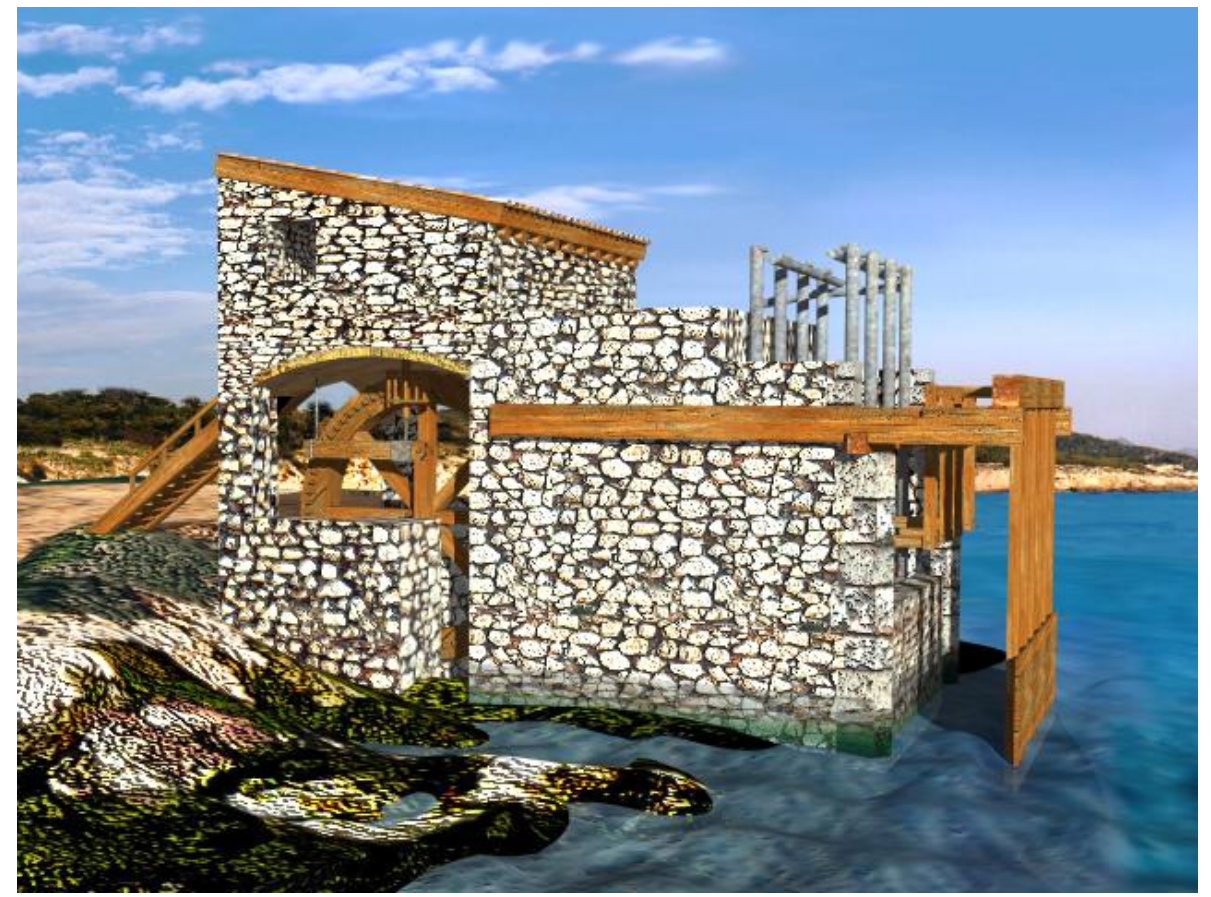

Figure 3. Virtual reconstruction of the flour mill.

The starting point was to define the criteria that would guide our decisionmaking according to the reliability of the information we had. In certain cases, we had to decide on the order in which these criteria should be applied, depending on the information available regarding specific details and related circumstances.

The criteria used to govern our decisions are listed below, in order of reliability. The section that follows provides further details on each point. 
- Observation and measurement of the existing remains

- Study of old photographs

- Analysis of original plans containing details of the system used to pump up water to the gathering pond

- Description of the layout and mode of operation of the complex made by an eyewitness in 1801

- Deductions made on the basis of known dimensions, information about the machinery used in other mills, and technical requirements that the mill would have had to comply with to operate

- Non-technical aspects such as construction costs and criteria related to creating a simple model that showed how the mill worked

\section{Observation and measurement of the existing remains}

On analyzing the remains of the mill, we obtained numerous measurements and information about the general size and orientation of the complex. We also obtained many ideas about the position of the mechanical parts of the installation.

Although the remains did not initially appear to provide much information about how the mill actually worked, they actually contained numerous features that helped us to interpret some of the documents consulted.

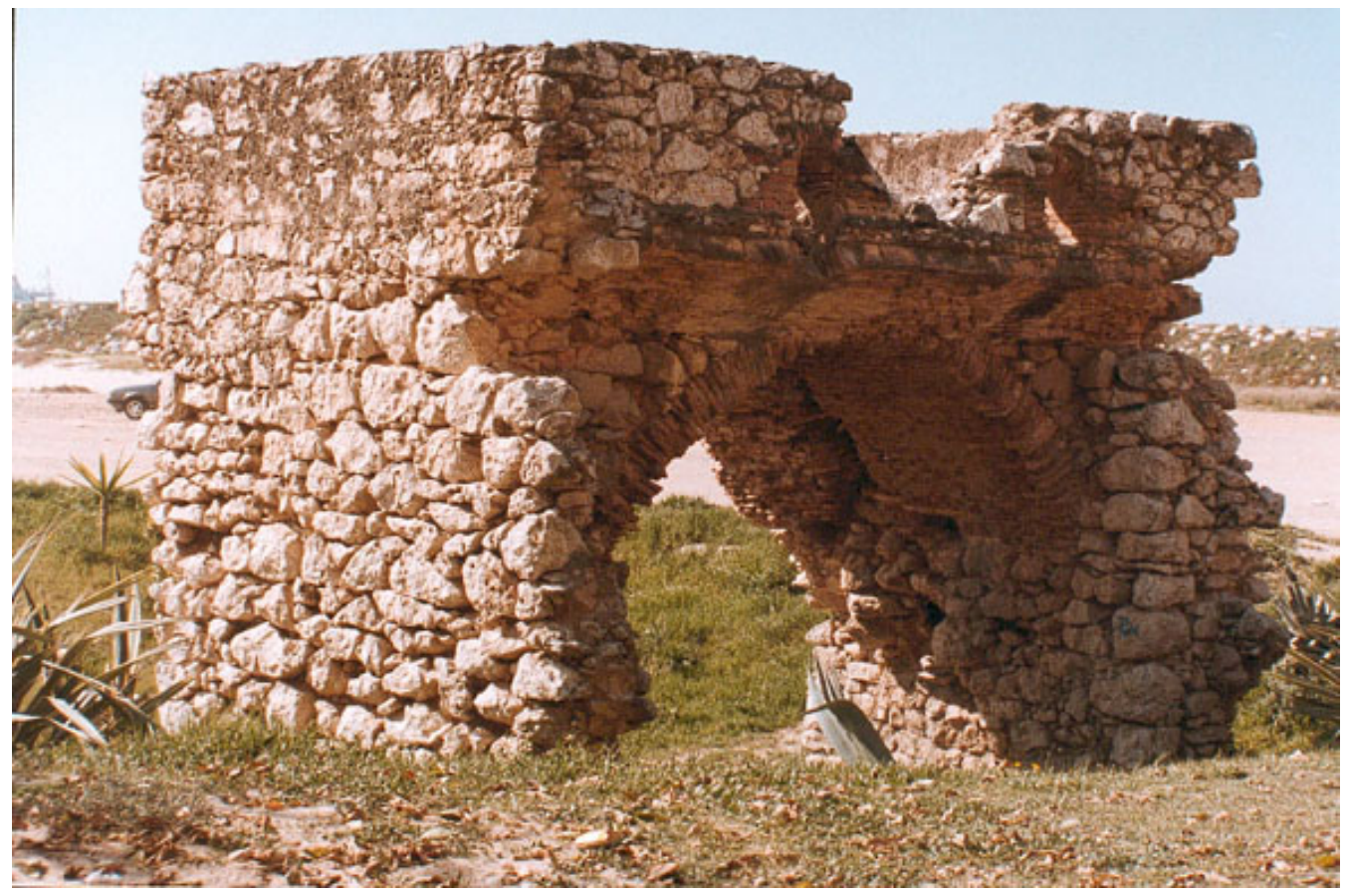

Figure 4. Current remains. Centre building with the gathering pond. 
Although the mill remains are obviously the most reliable source of information, the gradual deterioration of the building over the course of the years has destroyed certain features and made others difficult to interpret. For example, we were unable to determine whether the different wall thicknesses observed was part of the original design or simply a result of the passage of time.

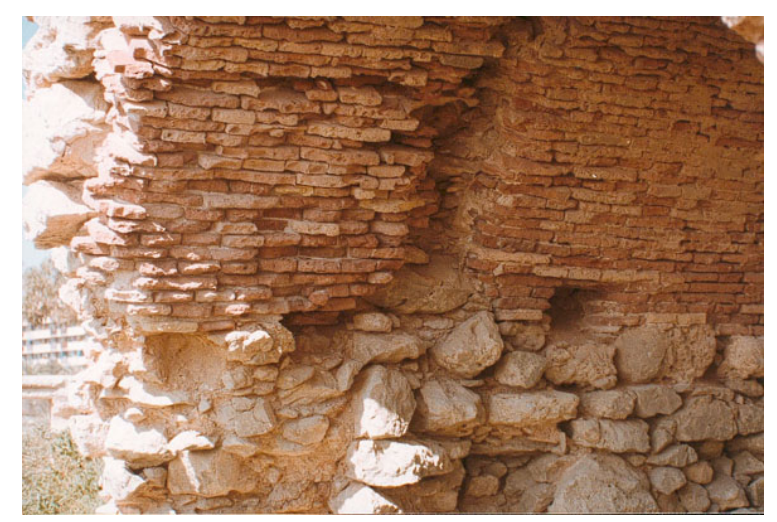

Figure 5. Current remains. Symmetrical cavities.

We were also unable to find a satisfactory explanation for the presence of two symmetrical cavities under the arch. Another feature observed was a possible smooth plaster finish on the brick arches.

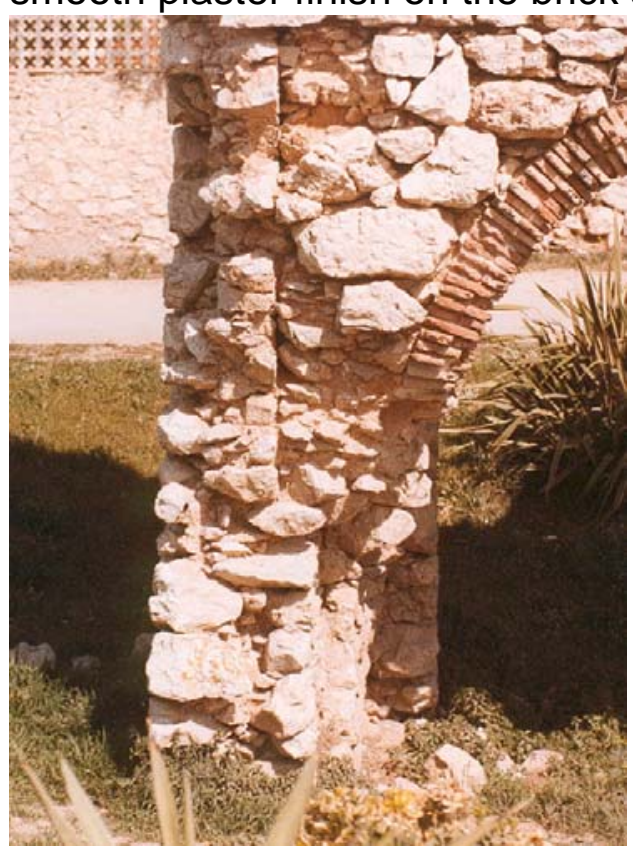

For the virtual reconstruction of the mill, we decided to create an exposed brick finish, in keeping with the building's current appearance.

We also simplified other aspects. For example, when constructing the walls, we ensured that these were fully upright and parallel to each other, even though this was not exactly the case in the original building.

Figure 6. Current remains. Wall with arch. 


\section{Study of old photographs}

We had several photographs dating from the early 19th century to the 1970s. Most of the photographs had been taken before the construction of the breakwater which had led to the formation of the beach in front of the lighthouse.

The most important details obtained from these photos were the shape, dimensions, and finish on the walls that extended seawards from the pond building and formed the room that housed the pumps.

We were also able to calculate the height from sea level to the pond by estimating the distance from a group of rocks next to the current remains to the rocks visible in a photograph but that are now buried under the sand.

Another important detail observed in these old photographs was a projection on the walls of the pump room. We believe that this acted as a support for the crossbeam that held the posts supporting the axle of the pendulums.

Finally, we were able to see the position of the mill complex with respect to the sea and to gain an idea of what the surrounding landscape looked like.

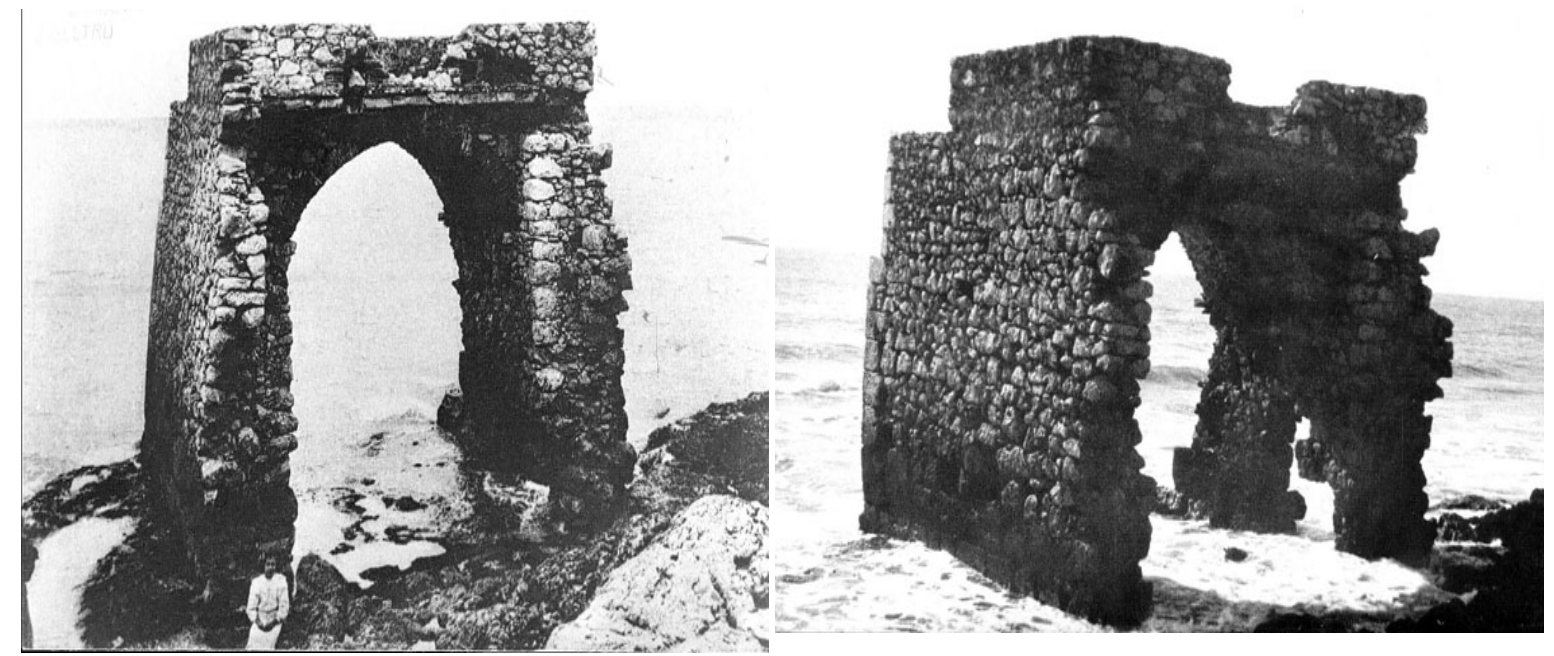

Figure 7. Original location. Walls with a projection extending seawards.

\section{Analysis of original building plans}

The only plans we located for the building were actually the most interesting ones as they described the innovative aspect of this mill. The plans featured a floor plan, elevations, and a cross-section of the wave-powered pumping system. Unfortunately, these plans contained general measurements only. They had been hand drawn and were missing crucial measurements such as the diameter of the pumps or the exact length of the pendulums, tie-beams, or rocker arms. They did, however, provide a rather good idea of how the mill worked. 


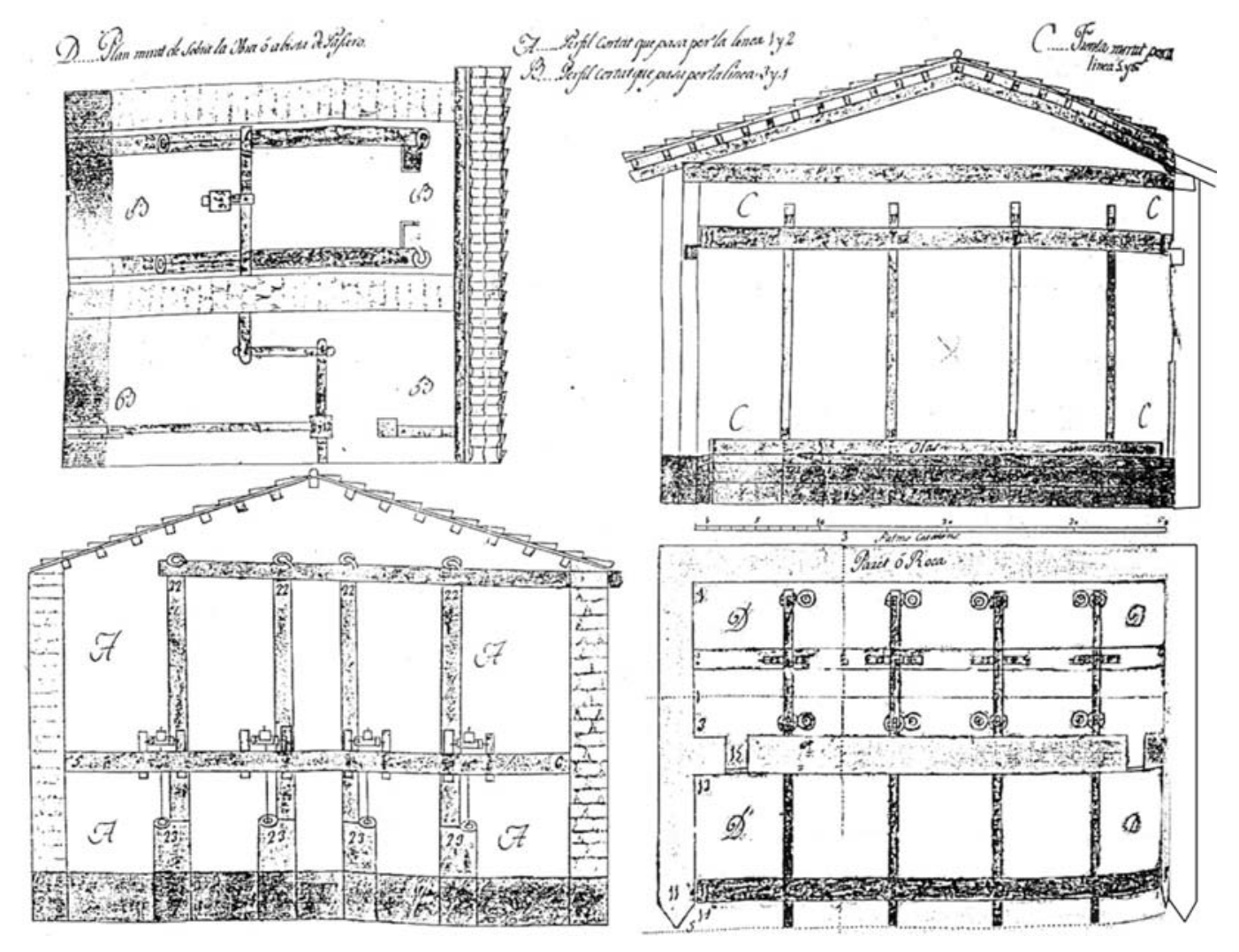

Figure 8. Original construction plans for the flour mill.

It is probably no coincidence that the only plans found were those that had been created by the inventor to justify the viability of the project. Flour mills had been around for some time and required few technical explanations, but Terrés' mill was different in that it was going to harness the force of the waves rather than traditional sources of power such as a river current or waterfall, or even the potential energy provided by tidal flow. Our inventor had to provide a convincing account of how he intended to harness this power to run a flour mill.

As we had no information on the dimensions of the pumping system used, we started by entering approximate measurements based on the relative sizes shown in the diagram. Using these measurements, we calculated the approximate amount of water that the system would have been able to pump up to the pond, presuming that the waves would have moved the pendulums from one extreme to the other and that the pumps had a piston diameter of $20 \mathrm{~cm}$. (These suppositions were necessary as calculating wave force is a complex process beyond the scope of this study. Neither did it make sense to base our calculations on the size of the pendulums or other components as we had no exact measurements for these either.)

The initial results obtained from the measurements entered into the model led to our changing the length of the pendulums to achieve a longer stroke length for the piston and to thus increase the amount of water that could be pumped.

It should be noted that an in situ description of the mill provided by an inhabitant 
of Vilanova in 1801 shows that the builder was not faithful to the plans in at least three aspects, marked with asterisks below.

\section{Eyewitness description of the mill}

The eyewitness description of the mill provided, without a doubt, the greatest insight into how the mill operated. This description was found in an article published in the Diario de Barcelona on August 9 and 10, 1801 (issues 221 and 222) (Annex B).

The article had been written by an observer who described to a friend the layout and operating mode of this unusual mill. He only mentioned a few estimated measurements, but they proved crucial to our gaining an idea of the layout of the different parts that made up the complex.

The article also provided other vital details, detailed below.

- The existence of three pendulums instead of the one specified in the plans $\left({ }^{*}\right)$.

It appears that Terrés decided to divide the original pendulum into three pendulums of equal length. From the layout shown in the diagram, it would seem logical that the pendulums on either extreme would have powered two pumps each and that the middle pendulum would have powered the other two sets of two pumps.

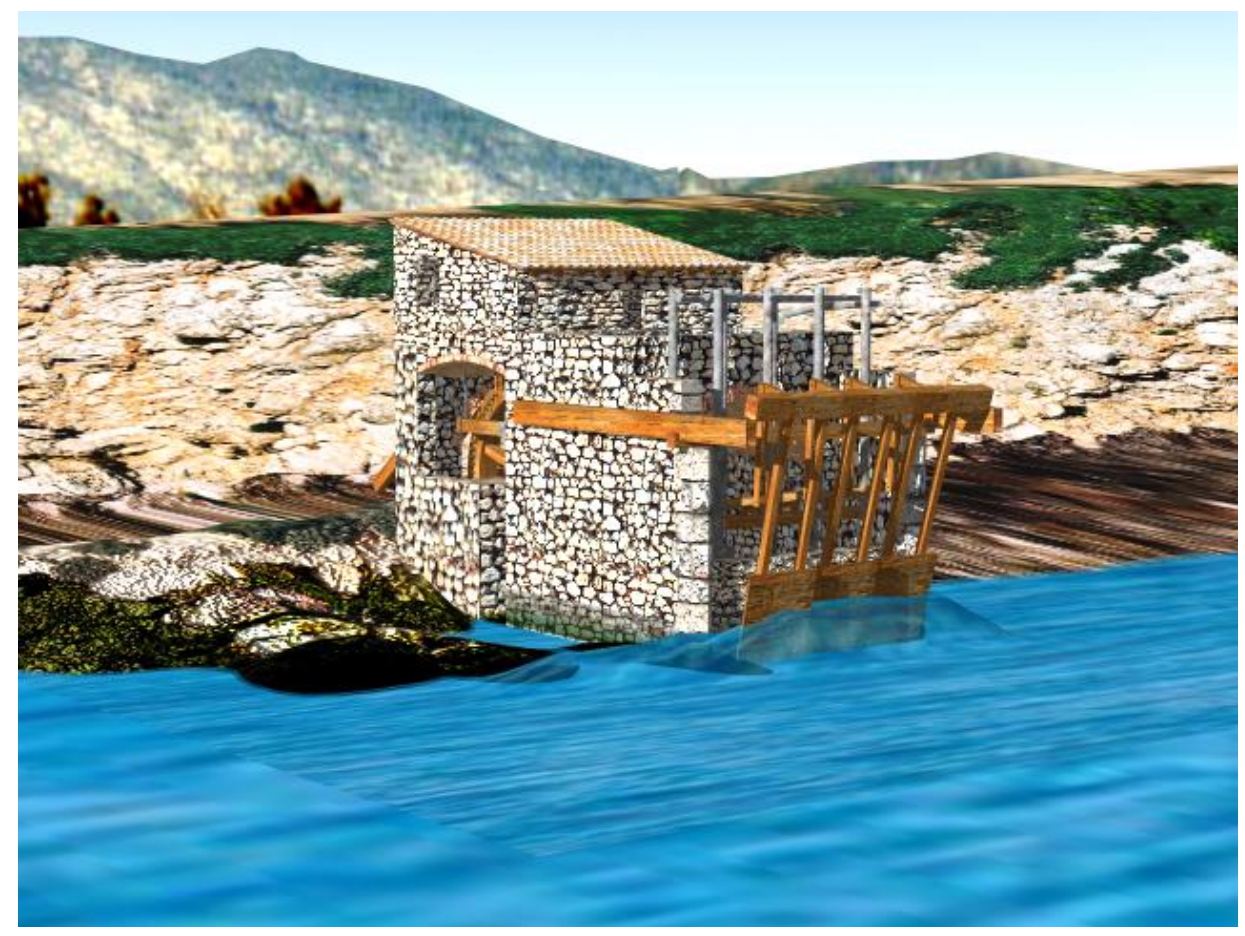

Figure 8. Virtual reconstruction of the mill: original appearance and location. 
- The means by which the pendulums were attached to the rest of the building (**).

"From the sides of the building facing the sea emerge two wooden posts or large beams that support an axle from which three pendulums hang in an oblong fashion..."

We had to imagine the form and length of these beams as well as the means by which they were attached to the building.

We calculated the height of the front wall, behind the pendulums, from the estimated measurements provided by the eyewitness, and imagined that it would be the same width as that of the side walls. The walls were probably thicker towards the bottom of the structure but we did not reflect this in the model to simplify matters.

- Roofless pump room (***).

Terrés' original plan had been to operate two waterwheels and four sets of millstones.

"Because this wheel has teeth on both sides, it can, by itself, move two lantern wheels,..."

The waterwheel in the model has teeth on both sides but we omitted other details. Because of the size of the wheel, its axle and spokes would have featured reinforcements that were not shown in the drawing. We can thus assume that the wheel had more wooden components than those shown. Nonetheless, we considered that such details were not crucial to understanding how the mill operated and would have considerably increased the computation power needed to create the final model.

- The layout of the milling room above the waterwheel.

- The vaulted walls around the wheel and the axle support mechanisms.

- Estimated sizes.

- Terrés' intention to make improvements.

"... it seems as if the inventor of the machine intends to increase the number of pumps or to place the existing pumps in a better location, using resources that he has not mentioned, and also, possibly to make the best possible use of the pendulums, by continually changing their position, to align them with the different directions of the waves of the sea.

- A general idea of the layout and operating mode of the mill.

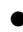

- The fact that the mill actually worked at some point.

“... whose result has provided us with very good flour for kneading and eating very white cakes." 
(*) The first difference with respect to the plans is the position of the pendulums and specifically the means by which these were attached to each other at the bottom, via paddles that absorbed the dashing of the waves. The plans featured just one pendulum, whereas the description mentioned three.

This change was probably made for technical reasons. Waves do not normally impact the coastline perpendicularly and would not move the pendulums uniformly across the structure. Furthermore, considerable force would have been required to move the pendulums, causing stress to the wooden structure from the moment the wave impacted one side to the time it reached the other. The longer the pendulum, the greater the stress and the greater the risk of damage or detachment.

The simplest way of reducing this stress would have been to divide the total length into several shorter lengths.

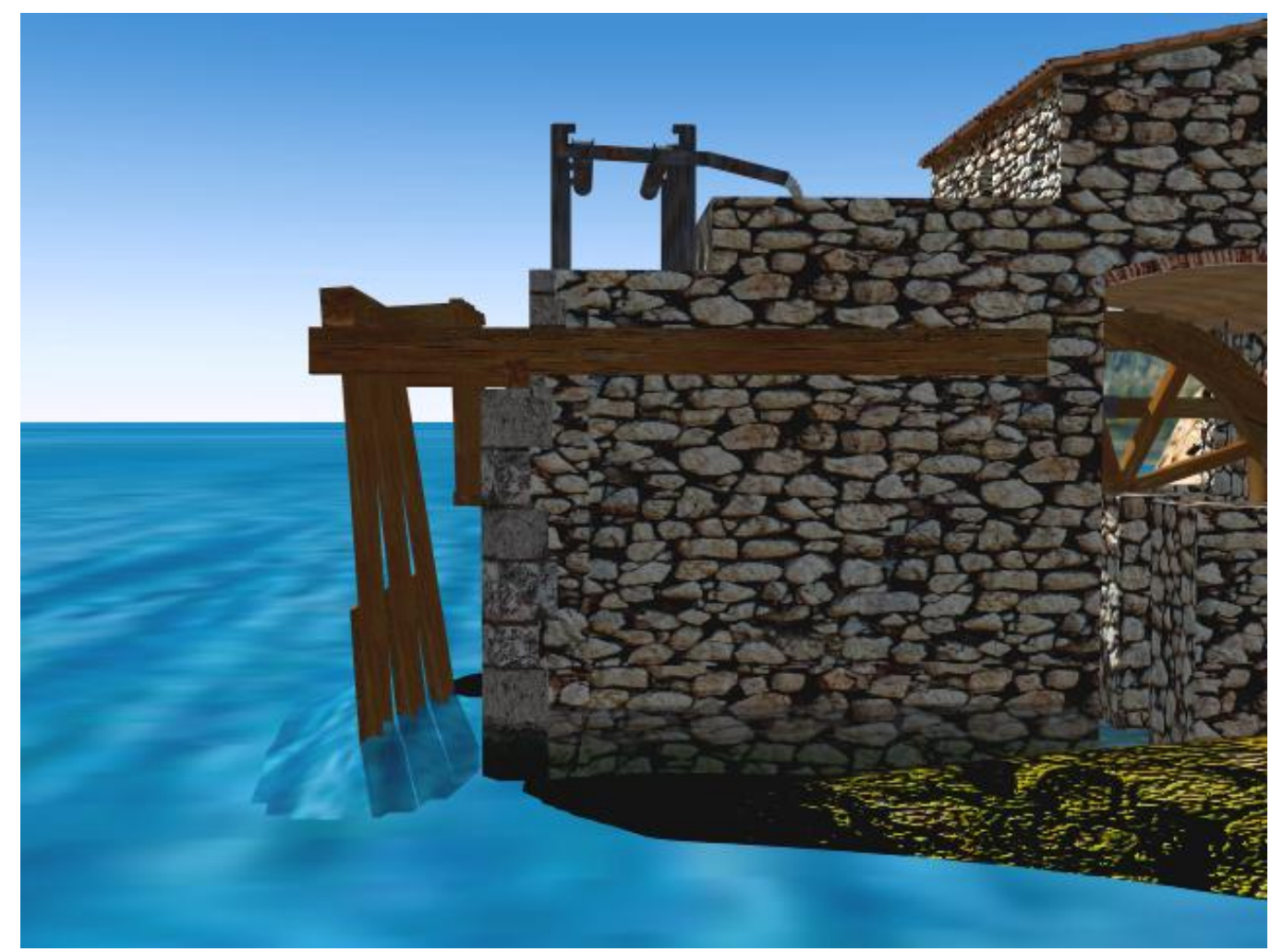

Figure 9. Note the lag between the different pendulums and the stress of the mechanism working as a single pendulum.

A better but more complicated and costly solution would have been to angle the pendulums according to the direction of the waves. This would also have improved the performance of the pumps as the pendulums would have received the maximum force of each wave. This theory is supported by the fact that the newspaper article mentioned the inventor's intention of improving performance by adding a system that would angle the entire structure towards the direction of the waves so that these would impact the pendulums perpendicularly. 
${ }^{(* *)}$ In the actual construction, the axle of the pendulums was supported by two beams that projected from the sides of the building rather than being enclosed by walls and a roof. This change would have saved on materials and building costs by eliminating the need to extend the walls out to sea.

$\left({ }^{* \star}\right)$ The eyewitness made no mention of a roof over the pump room, even those there was a double-sloped roof in the diagram. This change might also have been made to cut costs.

\section{Deductions}

Apart from the information obtained from the newspaper description, we were unable to locate any documents that shed light on the true dimensions, location, and shape of the remaining parts of the mechanical system. To calculate the diameter of the waterwheel, we analysed the distance between the holes that supplied the water to move the wheel and took into account the estimated diameter of six metres mentioned by our eyewitness. Because this seemed excessive, we finally decided on a diameter of five metres as this would have been the largest diameter that would have allowed the wheel to turn freely.

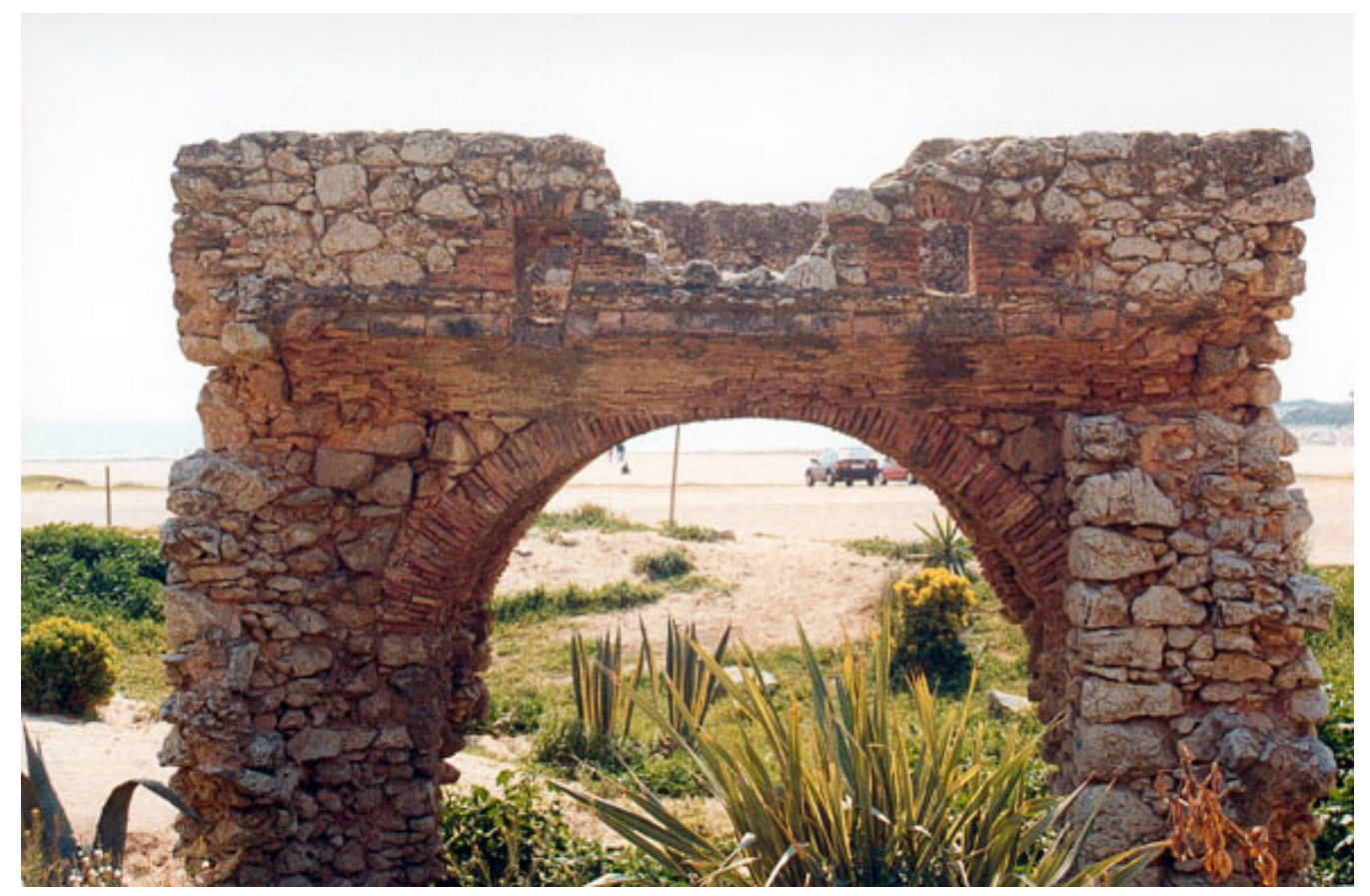

Figure 10. Note the holes in the wall of the pond room prepared for two waterwheels. From the information available, only one wheel and one set of millstone were installed.

We calculated the width of the waterwheel using known dimensions for other wheels with similar diameters. We found that these measurements varied greatly and that there was no set pattern for the relationship between wheel 
diameter and width. The sizes were calculated according to the amount of water available or the speed with which this was to be supplied to the wheel. In our case, the wheel had to be sufficiently wide to accommodate the eventual installation of four sets of mill wheels. For our calculations, we had to take into account the distance between the two water supply holes.

This space, measured in situ, was where two of the sets of mill wheels were to be located. Furthermore, the wheel had to be wide enough to allow it to collect all the water that fell from the holes, which were $31 \mathrm{~cm}$ wide. We finally decided on a wheel width of $50 \mathrm{~cm}$.

Using the dimensions calculated for the wheel and the distance between the two water supply holes, we were able to estimate the maximum diameter of the two centre millstones and, by extension, that of the other two. To further improve the accuracy of our estimations, we assumed that the original building would have been as wide as the remains and that the miller would have had to have enough space to pass between each set of millstones. We therefore decided on a diameter of $80 \mathrm{~cm}$ for each millstone. This gave us the initial information we needed to calculate the axle of the lantern wheel and its radius.

When the above measurements had been entered in the model, we saw that the diameter of the waterwheel was very large compared to that of the lantern wheel and would have caused the millstone to turn at a speed of 6 revolutions per minute. Because this speed was excessive, we changed the measurements and created as wide a diameter as possible for the lantern wheel, and thus reduced the speed with which the millstone would have turned. The final diameter of the lantern wheel was set at $32 \mathrm{~cm}$.

\section{Decisions}

The form of the central part of the building (the gathering pond room) and the walls of the pump room were determined on the basis of the photographs we had. As far as the rest of the building was concerned, however, we had to imagine many aspects and take certain decisions that could easily have gone another way. Our first assumption was that the width of the milling room would have been identical to that of the rest of the building given the fact that the walls of the pond room extended out towards the back. As far as the length was concerned, we assumed that it would have been proportional to the width and sufficient to house, in our case, four sets of millstones and the corresponding machinery.

In the description published in 1801, our eyewitness mentioned that the room housing the waterwheel was "surrounded by vaulted walls". We interpreted this information freely and continued the curve of the vault, which started in the gathering pond room, towards the back and joined it to a perpendicular curve on the back wall. Given the form in which this curve began and taking into account the shape of the typical Catalan brick arch of the time, we decided to maintain the symmetry and finish the curve in the same way as it began. 


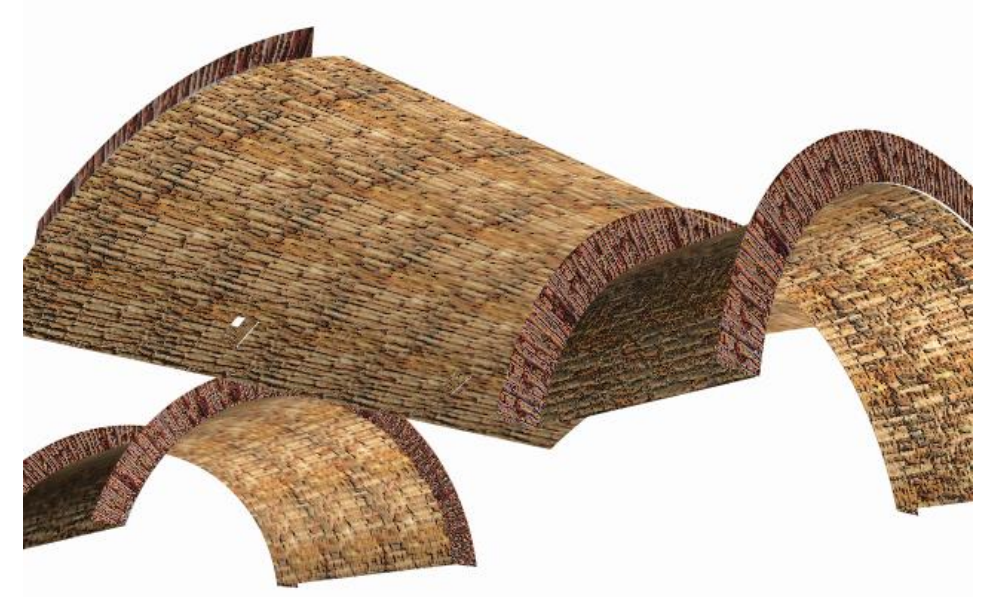

Figure 11. Close-up of the vaults from the model.

Probably to create an attractive building design and economise on construction material, Terrés had decided to leave the side and rear walls open, such that the waterwheel could be seen from the outside. Accordingly, we built half-height side walls, which served as a support for the waterwheel axle, just as our eyewitness had reported in his newspaper report.

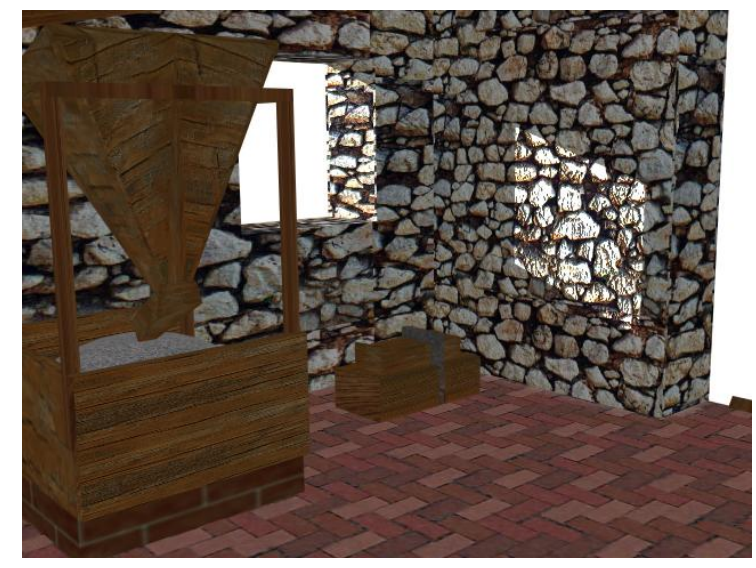

Figure 12. Close-up of the milling room.

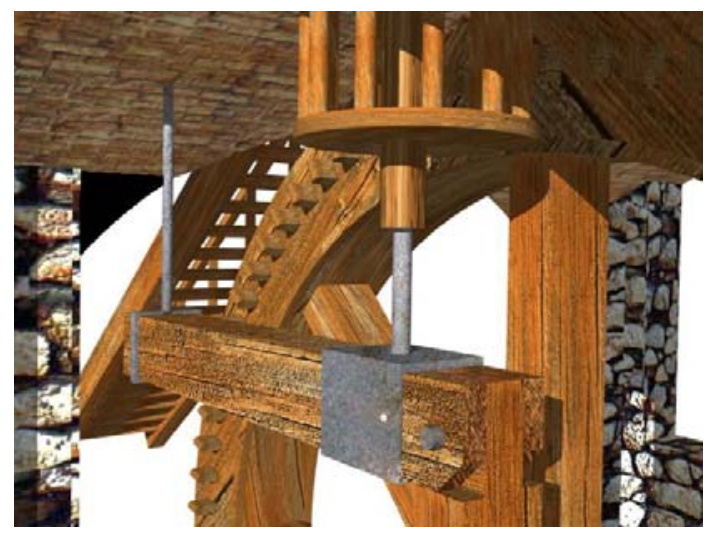

Figure 13. Close-up of the waterwheel and transmission system.

Because the milling room was the part of the complex for which we had the least information, we had to imagine what it might have been like. We decided that it would have been as wide as the rest of the building and large enough to house four sets of millstones and corresponding equipment.

To simplify matters, we decided to create a roof sloping down towards the gathering pond. We added three small windows and a door leading out to the back, which was accessed by a small wooden ladder.

With the exception of the back wall, which was provided with a thickness of 
$75 \mathrm{~cm}$, the other three walls were made identical to those of the rest of the building (thickness of $50 \mathrm{~cm}$ ).

\section{Conclusions}

\section{D drawings. Digitialisation of 3D models.}

Once we had defined the size and position of all the components of the model, we drew a 2D diagram which we then used to correctly enter the coordinates for all the elements in the 3D model.

\section{Exportation of 2D and 3D drawings to a virtual simulation program}

All the components were added to a virtual simulation program in small groups until the complete model of the mill had been created. Numerous changes were also made following importation.

\section{Creation of maps and textures}

The components of the mill were classified according to the material with which they had been made in the original mill. In the case of wood, which was the most common material used, we created a family of mobile components and another of fixed ones. Mapping is the process of applying a material to each object or component.

\section{Scene creation}

Once we had prepared the maps and textures, we used the materials editor to select a standard format and other personalised formats. These were given names and applied to the maps selected for each component. Once placed over the object, they were rendered to check that the orientation, proportion, and final result were correct.

\section{Animation and generation of videos}

To animate the mobile parts of the mill, we had to carefully define the movements of each component and synchronise them correctly.

As explained above, the video contains various sequences that have been put together. This permitted the application of certain effects such as the blending of images in the final edit. All the rendered images were compressed in order to view them once they had been created. For the final scenes, however, it would have been better to have compressed these images in the post-production stage to prevent the loss of image quality that occurred in certain cases. 


\section{References}

[1] Les Moulins, Jean Orsatelli Edita Jeanne Laffitte, 1979.

[2] Molinos de Mar, Luis Azurmendi Pérez. Edita Colegio oficial de arquitectos de Cantabria.S.A.U.R., 1985.

[3] Molinos de Viento del campo de Cartagena, Lucia Gómez / María Elena Montaner / Juana Pellicer.Editorial Regional de Murcia, 1981.

[4] L'Any dels Negats, Albert Virella i Blonda. Edita Consell Comarcal del Garraf, 1996.

[5] Butlletí de L'Associació d'Alumnes obrers de l'Escola Industrial de Vilanova i la Geltrú,

Núm 6, Gustau Galceran, 1924.De donde se extrajeron los artículos del Diario de Barcelona num 221 y 222 de los dias 9 y 10 de Agosto de 1801,.

[6] El Molí, La Sirena i Les Gavines, Artículo, Xavier García. núm. 21-24 de 'La Nostra Mar',

Publicación del Museo del Mar. Vilanova i la Geltrú, Junio 1984.

[7] El Molí de Mar a Villanueva y Geltrú, Artículo. 14 Diciembre 1974.

[8] El Molí de Mar de Vilanova i la Geltrú. Memoria sobre el estado de la cuestión, Francisco Conde Jiménez. Trabajo fin de curso de Historia de la ciencia y de la técnica. Universidad de Barcelona. Junio 1987.

[9] UPC-EPSEVG Estudio del molino de mar de Vilanova i la Geltrú. PFC Miguel Ausejo, 2000

[10] Arxiu històric de la ciutat, Barcelona. Registro político de representaciones del año 1799.

[11]Registro del Archivo histórico municipal de Vilanova i la Geltrú. A Industria: carpeta 2877. Correspondencia 1802 - 1822. 